\title{
Reduced Chemical Kinetic Mechanisms for Hydrocarbon Fuels
}

\author{
C.J. Montgomery, M.A. Cremer, M.P. Heap, J.-Y. Chen, \\ C.K. Westbrook, L.Q. Maurice
}

This article was submitted to $35^{\text {th }}$ American Institute of Aeronautics and Astronautics/Association for the Study of Medical Education/American Society for Engineering Education Society of Automotive Engineers Joint Propulsion Conference and Exhibit, Los Angeles, CA, June 20-24, 1999

\section{December 10, 1999}

Lawrence

Livermore

National

Laboratory 


\section{DISCLAIMER}

This document was prepared as an account of work sponsored by an agency of the United States Government. Neither the United States Government nor the University of California nor any of their employees, makes any warranty, express or implied, or assumes any legal liability or responsibility for the accuracy, completeness, or usefulness of any information, apparatus, product, or process disclosed, or represents that its use would not infringe privately owned rights. Reference herein to any specific commercial product, process, or service by trade name, trademark, manufacturer, or otherwise, does not necessarily constitute or imply its endorsement, recommendation, or favoring by the United States Government or the University of California. The views and opinions of authors expressed herein do not necessarily state or reflect those of the United States Government or the University of California, and shall not be used for advertising or product endorsement purposes.

This is a preprint of a paper intended for publication in a journal or proceedings. Since changes may be made before publication, this preprint is made available with the understanding that it will not be cited or reproduced without the permission of the author.

This report has been reproduced directly from the best available copy.

Available to DOE and DOE contractors from the Office of Scientific and Technical Information P.O. Box 62, Oak Ridge, TN 37831

Prices available from (423) 576-8401 http://apollo.osti.gov/bridge/

Available to the public from the National Technical Information Service

U.S. Department of Commerce 5285 Port Royal Rd., Springfield, VA 22161 http://www.ntis.gov/

OR

Lawrence Livermore National Laboratory Technical Information Department's Digital Library http://www.llnl.gov/tid/Library.html 
AIAA 99-2220

\section{Reduced Chemical Kinetic Mechanisms for Hydrocarbon Fuels}

C. J. Montgomery, M. A. Cremer, M. P. Heap

Reaction Engineering International

Salt Lake City, UT

J.-Y. Chen

University of California, Berkeley

Berkeley, CA

C. K. Westbrook

Lawrence Livermore National Laboratory

Livermore, CA

L. Q. Maurice

Air Force Research Laboratory

Wright-Patterson Air Force Base, $\mathrm{OH}$

35th AIAA/ASME/SAE/ASEE Joint Propulsion

Conference and Exhibit

20-24 June 1999

Los Angeles, California 


\title{
REDUCED CHEMICAL KINETIC MECHANISMS FOR HYDROCARBON FUELS
}

\author{
Christopher J. Montgomery*, Marc A. Cremer $\dagger$, Michael P. Heap $\ddagger$ \\ Reaction Engineering International \\ Salt Lake City, UT \\ Jyh-Yuan Chen $\$$ \\ University of California, Berkeley \\ Berkeley, CA \\ Charles K. Westbrook \\ Lawrence Livermore National Laboratory \\ Livermore, $\mathrm{CA}$ \\ Lourdes Q. Maurice\# \\ Air Force Research Laboratory \\ Wright-Patterson Air Force Base, OH
}

\begin{abstract}
Using CARM (Computer Aided Reduction Method), a computer program that automates the mechanism reduction process, a variety of different reduced chemical kinetic mechanisms for ethylene and $n$-heptane have been generated. The reduced mechanisms have been compared to detailed chemistry calculations in simple homogeneous reactors and experiments. Reduced mechanisms for combustion of ethylene having as few as 10 species were found to give reasonable agreement with detailed chemistry over a range of stoichiometries and showed significant improvement over currently used global mechanisms. The performance of reduced mechanisms derived from a large detailed mechanism for $n$-heptane was compared to results from a reduced mechanism derived from a smaller semi-empirical mechanism. The semi-empirical mechanism was advantageous as a starting point for reduction for ignition delay, but not for PSR calculations. Reduced mechanisms with as few as 12 species gave excellent results for $n$-heptane/air PSR calculations but $16-25$ or more species are needed to simulate $n$-heptane ignition delay.
\end{abstract}

*Senior Engineer, AIAA Member

† Manager, Environmental Technologies

$\ddagger$ President

§Associate Professor, Dept. of Mechanical Engineering

y) Program Leader for Computational Chemistry

\#Research Scientist, AIAA Associate Fellow

Copyright 191999 The American Institute of Aeronautics and Astronautics Inc. All rights reserved.

\section{INTRODUCTION}

Detailed chemical kinetic descriptions of hydrocarbon combustion may require the tracking of hundreds of chemical species and thousands of reaction steps. For the foreseeable future, CPU time and computer memory limitations will prohibit implementation of fully detailed descriptions of combustion chemistry into 3-D CFD simulations of practical devices.

Issues such as ignition, flame stabilization, combustion efficiency, and pollutant formation are extremely important in the design of the next generation of aircraft engines. Accurate simulation of these phenomena requires that significant chemical kinetic detail be retained in computer models.

Within CFD simulations, the number of species tracked impacts the memory usage and CPU time. As a result, it is important to use any available methods to minimize this number while retaining essential features of the detailed chemistry. The number of species required for simulation of combustion processes depends on the nature of the phenomenon, and the type of information desired from the simulation.

The recent development of comprehensive, validated, detailed mechanisms for combustion of large hydrocarbons ${ }^{1.23}$ is a significant step forward. Reduced chemical kinetic mechanisms that can represent important aspects of the behavior of these detailed mechanism using few enough scalars that they can be implemented into CFD simulations offer large potential improvement in the modeling of practical combustion devices. 
The approach used here is to reduce mechanisms by employing steady-state assumptions ${ }^{4,5,6}$. In this work we have used CARM (Computer Assisted Reduction Method) ', a computer program that automates the reduction procedure, allowing large, detailed mechanisms to be reduced quickly.

Other approaches to chemistry reduction include intrinsic lower manifold methods ${ }^{8}$, computational singular perturbation ${ }^{9.16}$, rate-controlled constrained equilibrium ${ }^{11}$, and repro-modeling ${ }^{12}$. Griffiths ${ }^{13}$ gives a useful review of mechanism reduction techniques.

\section{AUTOMATED MECHANISM REDUCTION}

Mechanism reduction using steady-state assumptions has been extensively applied to hydrogen and methane combustion; many examples can be found in the volumes edited by Smooke, and Peters and Rogg ${ }^{6}$. In this work we use an automated technique to apply these methods to larger mechanisms for larger hydrocarbons.

There are four basic steps in the formulation of a reduced chemical kinetic mechanism:

1) Identification of a short or "skeletal" mechanism containing only the most essential species and reaction steps of the detailed mechanism.

2) Identification of appropriate steady-state approximations.

3) Elimination of reactions through use of the algebraic relations obtained in step 2 .

4) Solution of the coupled and nonlinear set of algebraic equations obtained in the previous steps to find the reaction rates of the remaining species.

CARM automates this procedure, producing source code for the calculation of the chemical source terms defined by the reduced mechanism. As inputs, CARM uses a set of test problem results representing conditions of interest (currently restricted to PSR solutions) to rank species by the error induced by assuming they are in steady state. The subroutine produced by CARM contains code that iteratively solves the coupled, nonlinear set of algebraic equations giving the concentrations of the steady-state species.

\section{DETAILED MECHANISMS}

In this work, we have chosen to use $n$-heptane and ethylene for application of the CARM reduction technology. Normal heptane is a fairly large hydrocarbon of a weight approaching that found in aviation fuels. The recent publication of a very detailed mechanism $^{3}$ and a much shorter semi-empirical mechanism $^{2}$ make this fuel ideal for the study of reduced mechanisms for larger hydrocarbons. Ethylene is a considerably simpler fuel than $n$-heptane, but we are unaware of any previous work on reduced mechanisms of the type we consider here for ethylene. Ethylene is also a fuel of interest in scramjet combustion research ${ }^{14}$.

Reduced mechanisms can perform no better than the detailed mechanisms on which they are based. Thus, it is important to select the best available detailed mechanisms for reduction. An updated version of the propane mechanism of Westbrook and Pitz ${ }^{15}$ is used as the detailed mechanism for ethylene combustion. Two different mechanisms were used to create reduced mechanisms for $n$-heptane combustion.

The detailed $n$-heptane mechanism of Curran et al. ${ }^{3}$ is intended to cover the entire range of conditions from low temperature $(600-900 \mathrm{~K})$ pyrolysis and oxidation to high temperature combustion. For our investigation, we have focused on a subset of this mechanism derived using sensitivity analysis to remove those reaction steps and species that are only important at lower temperatures $(<900 \mathrm{~K})$. With 105 species and 808 elementary steps, this subset mechanism, which we will refer to as "CGPW" from the first letters of the authors of the original detailed mechanism's last names, is still a large and complex mechanism. This mechanism is much larger, and models combustion of a significantly more complex fuel, than has previously been attempted using automated reduced mechanism techniques. Previous studies have focused mainly on combustion of methane ${ }^{7,16-18}$.

In contrast, the $n$-heptane mechanism of Held et $\mathrm{al}^{2}{ }^{2}$ was selected because of its relative simplicity. This mechanism is able to give good comparisons to experiments with comparatively very few species by empirically modeling the initial fuel breakdown. A very detailed mechanism, such as the CGPW mechanism, contains reaction steps for abstraction of $\mathbf{H}$ atoms from the fuel by a number of radical species to form several heptyl radical isomers. These heptyl radicals then decompose through a number of routes to form various species with two to five carbon atoms. Held et al. ${ }^{2}$ achieve considerable simplification by bypassing the formation of assorted heptyl radicals and their breakdown by allowing the $n$-heptane fuel to decompose directly into smaller reaction products, often with three or four products on the right-hand-side of an "elementary" reaction step. For brevity we will hereafter refer to this mechanism and reduced mechanisms based it by the initials "HMD" after the authors' initials. 


\section{RESULTS}

We have compared results of reduced mechanisms using various numbers of species and elementary reactions with those of the full mechanism, and in some cases, experiments in perfectly stirred reactor (PSR) and thermal ignition delay calculations. The ignition delay calculations are performed in a plug flow reactor (PFR) configuration.

We have created reduced mechanisms for ethylene/air combustion designed to work over a range of equivalence ratios. We have also attempted, by choosing appropriate input test problems, to create reduced mechanisms for ethylene tailored to the modeling of ignition delay.

For $n$-heptane we have examined how the choice of the type of starting mechanism, either very long and detailed (CGPW) or shorter and semi-empirical (HMD) impacts the results of mechanism reduction.

\section{Reduced Mechanisms for Ethylene}

In our study of reduced kinetic mechanisms for ethylene, we have examined the effects of the number of species treated kinetically, (as opposed to assuming they are in steady state) as well as the influence of the type of problems input to CARM during the mechanism reduction process. As described earlier, these input problems, which presently are limited to PSR solutions, are used by CARM to rank the errors for assuming each species is in steady state and to choose the elementary reaction step to be eliminated for each steady state relation. Thus, the reduced mechanisms produced by CARM are in a sense tuned or optimized to the conditions of the input problems. Nevertheless, it should be remembered that mechanism reduction using CARM is not simply a curve-fitting process in which the results of the input problems are trivially reproduced. If the detailed mechanism is reduced too far, that is, too many species are assumed to be in steady state, the input problem results will not be well reproduced. Reproducing the input problems is a minimum test of a reduced mechanism, especially if the input problems cover only a narrow range of conditions. A more difficult test is how well a reduced mechanism performs under off-design conditions.

For ethylene we have examined reduced mechanisms with 10,15 , and 20 species. In describing the number of species in a mechanism inert diluents such as nitrogen or argon are included. In this paper we show results for two sets of mechanisms that have been "tuned" through selection of the set of input PSR solutions. The input problems for the first set of mechanisms were PSR solutions for ethylene/air mixtures at $1.0 \mathrm{~atm}$., initial temperature $300 \mathrm{~K}$, equivalence ratio, $\phi=1.0$, with adiabatic conditions, and residence times varying from $10^{-2}$ to $5 \times 10^{-5} \mathrm{sec}$, and for $\phi=2.0$ with residence times of 0.01 to $5 \times 10^{-4} \mathrm{sec}$ This range of residence times gives conditions from near equilibrium to near blowout.

We have attempted to tailor a second set of mechanisms to reproduce results of the detailed chemistry for thermal ignition of stoichiometric ethylene-air mixtures for initial temperatures of 1400 $2000 \mathrm{~K}$. The input problems selected were constanttemperature PSR solutions over the temperature range of interest for residence times of $10^{-2}$ to $10^{-5} \mathrm{sec}$. This set of mechanisms is designated "ig" for "ignition".

In comparing reduced mechanisms for ethylene over a range of conditions and problems, significant sensitivity to the choice of problems input to CARM was found. Reduced mechanisms created using only stoichiometric PSR inputs gave excellent results for the design conditions and for fuel-lean combustion, but produced significant errors for fuel rich mixtures. Reduced mechanisms created with PSR solutions covering a range of equivalence ratios were able to give reasonable agreement for rich situations, at the cost of worse performance for stoichiometric and lean conditions. As the number of species retained in the reduced mechanisms was increased, the range of problems, for which satisfactory agreement with detailed chemistry could be obtained increased.

Figures 1-4 compare results of PSR calculations using detailed chemistry and the reduced ethylene mechanisms using 10, 15, and 20 species. All PSR calculations were performed using the code of Glarborg et al. ${ }^{19}$ Figures 1-3 show temperature for $\phi=0.5,1.0$, and 2.0. Figure 4 shows CO mole fraction for $\phi=1.0$. Results for other species and equivalence ratios (not shown) are similar. The results for the reduced mechanisms with 15 and 20 species are nearly indistinguishable from those for detailed chemistry for all quantities. Errors are larger for the 10-species mechanism.

We have made comparisons of the reduced mechanisms produced by CARM with "global" reduced kinetics for ethylene combustion from the literature. These models use short sets of Arrhenius-form reactions to approximate the overall combustion process. The two global models for ethylene combustion that were examined were recently used in scramjet combustor simulations $^{14}$ and are considered "state-of-the-art". These are a three-step model with seven species developed by researchers at the Air Force Research Laboratory ("global7"), and a 10-step mechanism with 10 species $^{20}$, which we designate "global10". 
Figure 5 compares temperatures predicted by the detailed mechanism, the global 7- and 10-species mechanisms, and to the 10 -species reduced mechanism for a ethylene-air combustion in an atmospheric pressure PSR. Comparison to the 10-species reduced mechanism is the most fair, because this reduced mechanism and the global mechanisms use a similar number of species and are intended for a wide range of conditions.

The global mechanisms were undoubtedly not optimized for a stoichiometric PSR. Both were found to underpredict fuel consumption and heat release, and as a result, predict temperatures that are too low and PSR blowout at residence times over an order of magnitude larger that predicted using detailed chemistry. The CARM-produced reduced mechanisms are clearly superior for this application.

Ignition delay times were calculated for a stoichiometric mixture of ethylene and air at 1 atm using the SENKIN code ${ }^{21}$, assuming the system is a constant pressure, adiabatic plug flow reactor (PFR). Results are shown in Fig. 18. The 15- and 20-species reduced mechanisms tailored to ignition delay give excellent agreement with detailed chemistry. None of the other mechanisms tested performed satisfactorily. The 7- and 10-species global mechanisms performed better than the CARM-generated reduced mechanisms with equal or greater numbers of species. When CARM is extended to include the possibility of PFR input problems, modeling of ignition delay should improve.

Nevertheless, the success of tailoring reduced mechanisms to the ignition delay problem is shown by the difference in the results for the two 20-species reduced mechanisms, one of which was optimized for ignition delay while the other was not. Table 1 shows that the species included in these mechanisms differ only in one instance; $\mathrm{HO}_{2}$ is substituted for $\mathrm{CH}_{3}$ in the ignition mechanism. However the difference in the performance of the mechanisms for modeling thermal ignition is quite pronounced. It was also found that mechanisms not designed for ignition delay could give good results if they were created for the correct composition.

These results show that thermal ignition is a considerably more difficult problem than the PSR. While the PSR problem requires a steady-state solution at a range of burning conditions, thermal ignition requires accurate modeling of all steps of fuel breakdown, initial fuel fragment oxidation through near equilibrium conditions. It is therefore not surprising that a large number of species or a mechanism tuned to a very specific set of conditions is required.

\section{Reduced Mechanisms for $n$-Heptane}

Normal heptane $\left(n-\mathrm{C}_{7} \mathrm{H}_{16}\right)$ was chosen as a fuel for study because it is among the largest hydrocarbon fuels for which comprehensively validated detailed kinetic mechanisms exist. Normal heptane is also advantageous in that two recently published mechanisms of very different characters exist for modeling $n$-heptane combustion. These are the large, very detailed mechanism of Curran et al. ${ }^{3}$ (which we refer to as "CGPW") and the shorter, semi-empirical mechanism of Held et al. (which we designate "HMD").

In creating reduced mechanisms for $n$-heptane, we wish to test the hypothesis that the considerable human effort and insight that went into the formulation of the HMD mechanism would pay off in greater accuracy for the same number of species, or in fewer species being required to get the same degree of accuracy. To this end we have created reduced mechanisms from the CGPW mechanism with 25,20 , and 16 species and from the HMD mechanism with 16,12 , and 9 species. The $n$-heptane reduced mechanisms are designated by their parent mechanism (CGPW or HMD) and a number giving the number of species included kinetically, including a diluent.

The six $n$-heptane reduced mechanisms examined here were generated with input PSR solutions for equivalence ratios $\phi=1$ and $\phi=2$, with residence times chosen to give conditions ranging from near blowout to near equilibrium. The reduced mechanisms are compared to detailed chemistry for PSR's for $\phi=1.0$. The results for rich and lean conditions (not shown) are similar. Ignition delay results are compared to detailed chemistry and to the experiments of Vermeer et al. ${ }^{22}$ No $n$-heptane reduced mechanisms designed specifically to model thermal ignition were created.

Figures 7-10 show PSR results for detailed and reduced chemistry for the CGPW and HMD mechanisms for $\phi=1.0$. Temperature, $\mathrm{OH}, \mathrm{CO}$, and fuel mole fractions are shown. The reduced mechanism HMD9 does not include $\mathrm{OH}$ as a kinetically calculated species so no $\mathrm{OH}$ results are shown for it.

It can be seen from Figs. 7-10 that the detailed CGPW and HMD mechanisms disagree substantially for these conditions with temperature differences up to about $100 \mathrm{~K}$, as well as large disagreement in species mole fractions. Both of these mechanisms have been extensively validated against experiments, although not at the generic conditions used here. However, both detailed mechanisms agree well with measurements for ignition delay. Though the reasons for the disagreements are not clear, they give a consistent picture, with HMD always predicting lower temperatures, less fuel consumption, and higher 
concentrations of radical species. Since the purpose of this work was to apply and examine a mechanism reduction technique (CARM) and not to compare detailed mechanisms, we shall hereafter concern ourselves only with the level of agreement between detailed and reduced chemistry.

Overall, the agreement between detailed and reduced chemistry in Figures 7-10 is quite good. With a few exceptions, the expected trend of improving agreement with detailed chemistry as the number of kinetically treated species in the reduced mechanism increases is seen. Somewhat surprisingly, clear evidence does not emerge in the PSR data that starting with a smaller, semi-empirical detailed mechanism results in smaller reduced mechanisms with the same degree of fidelity to the parent or better agreement with detailed chemistry for the same number of species. This may reflect the fact that both detailed mechanisms model the same complex underlying process. The minimum number of independent variables needed to achieve a given level of agreement may depend more on the actual chemical process than on the starting point for mechanism reduction. However, it will be shown later that the HMD reduced mechanisms do perform better with fewer species for ignition delay. The reason that this effect is not seen in the PSR data is not known.

Reduced mechanisms based on the HMD detailed mechanism may perform better in an important area that has not been studied quantitatively in this work. Even with the same number of species being treated kinetically, reduced mechanisms based on HMD will require less CPU time for computation of the chemical source terms than those based on larger mechanisms. A smaller starting mechanism means fewer steady-state species to be solved for iteratively, and fewer elementary rates to be computed.

Figures 11 and 12 show ignition delay results for one of the conditions studied by Vermeer et al. ${ }^{22}$ The mixture is stoichiometric $n$-heptane/oxygen diluted with $70 \%$ argon. In these experiments ignition was initiated by a reflected shock so the system is modeled as a constant-volume PFR. Results are shown in separate figures for the CGWP and HMD mechanisms for clarity. We wish to point out that none of the $n$-heptane mechanisms were tailored for ignition delay and the experimental conditions we are attempting to simulate are quite different from the conditions (stoichiometric and rich PSR's at $1.0 \mathrm{~atm}$.) for which these reduced mechanisms were generated.

Figures 11 and 12 show that the detailed CGPW and HMD mechanisms agree very well with the experimental data. The agreement of the reduced mechanisms with detailed chemistry and experiment is not as good as for the PSR's or for the ethylene ignition delay calculations. This is probably because experimental conditions (composition, and pressure) are significantly different from those for which the reduced mechanisms were generated. As with the ethylene results, the quality of the ignition delay predictions drops markedly with the number of independent species in the approximation.

For both ethylene and $n$-heptane the predicted ignition delay time decreases steadily with decreasing numbers of species retained kinetically in the reduced mechanism. This may be because reduced mechanisms with fewer kinetically-treated species do a poorer job modeling the initial breakdown of the fuel, which is critical in predicting ignition times. It may be speculated that as the mechanism is simplified further, this aspect of the process is given increasingly approximate treatment, especially for reduced mechanisms not designed for ignition delay. The more globally-oriented fuel breakdown rates given calculated by small reduced mechanisms may work reasonably well in fully burning situations, but these fully burning rates will be too fast for lower temperature thermal ignition.

Figures 11 and 12 show the improved performance of mechanisms based on the smaller HMD mechanism that we looked for but failed to find unambiguously in the PSR cases. Notice that reduced mechanism HMD16 agrees with its parent mechanism and with experiment at least as well as CGWP25 and much better than CGWP16. It is not clear why this improvement is seen for ignition delay, but not for the PSR calculations.

\section{CONCLUSIONS}

The results presented here demonstrate that the automated chemical kinetic mechanism reduction strategy employed by CARM can be applied to detailed mechanisms for larger hydrocarbon fuels. These reduced mechanisms can be applied over a range of conditions and for a variety of problems.

For any engineering approximation, the level of detail required depends on the exact problem to be analyzed and the information desired. This has proven to be entirely true for reduced mechanisms. It was shown that for ethylene and $n$-heptane that as few as 12-15 species could give excellent agreement for PSR calculations near the design conditions of the reduced mechanism. At the other extreme it was found that 25 species may not give satisfactory results for $n$-heptane ignition delay when the reduced mechanism is used at off-design conditions. Overall, thermal ignition is a more difficult problem for reduced mechanisms, requiring either more independent species or a more 
narrowly focused mechanism. We believe that this is largely because thermal ignition is a more complex phenomenon than PSR combustion, requiring accurate modeling of comparatively low temperature initial fuel pyrolysis and oxidation through rapid high temperature burning.

It was found that using constant-temperature PSR inputs, that improved reduced mechanisms for modeling thermal ignition could be generated

We have compared reduced mechanisms based on the large, detailed, high-temperature subset of the $n$-heptane mechanism of Curran et al. (1998) (CGPW), and the much smaller, semi-empirical n-heptane mechanism of Held et al. (1997) (HMD). The two detailed mechanisms differ significantly when used in PSR calculations, but agree well with experimental data and each other for ignition delay. In the PSR calculations, no significant improvement was seen in the performance of mechanisms with the same number of species for the HMD mechanism, as might be expected. That is reduced mechanisms with the same number of species gave about the same degree of agreement with their parent mechanisms for PSR's. Significant improvement was seen, however for ignition delay calculations. The 16-species reduced mechanism based on the HMD mechanism was far superior to the reduced 16-species reduced mechanism based on the CGWP mechanism and gave results similar to the 25species reduced mechanism based on the CGWP mechanism

\section{ACKNOWLEDGMENTS}

This work was supported by the U.S. Air Force under DoD Phase I SBIR contract no. F33615-98-C2831. The authors wish to thank Prof. Adel Sarofim for helpful insights and Mr. Robert Seeley for help with data reduction.

\section{REFERENCES}

1. Maurice, L.Q., Ph.D. Thesis, University of London, 1996.

2. Held, T.J., Marchese, A.J., and Dryer, F.L., Combust. Sci. and Tech. 123:107-146, 1997.

3. Curran, H.J., Gaffuri, P., Pitz, W.J., and Westbrook, C.K., Comb. Flame. 114:149-177, 1998.

4. Chen, J.-Y., Combust. Sci. and Tech. 57:89-94, 1988.

5. Smooke, M.D. (Ed.), Reduced Kinetic Mechanisms and Asymptotic Approximations for Methane-Air Flames, Springer-Verlag, Berlin, 1991.
6. Peters, N. and Rogg, B, (Eds.) Reduced Kinetic Mechanisms for Applications in Combustion Systems, Springer-Verlag, Berlin, 1993.

7. Chen, J.-Y., Workshop on Numerical Aspects of Reduction in Chemical Kinetics, CERMICS-ENPC, Cite Descartes, Champus sur Marne, France, Sept. 2, 1997.

8. Maas, U. and Pope, S. B., Combust. Flame 88:239264, 1992.

9. Lam, S.H., and Goussis, D.A., Twenty-Second Symposium (International) on Combustion, The Combustion Institute, Pittsburgh, pp. 931-941, 1988.

10. Massias, A., Diamantis, D., Mastorakos, E., and Goussis, D.A., Combust. Flame 117:685-708, 1999.

11. Keck, J.C., Prog. Energy Combust. Sci. 16:125-154, 1990.

12. Turanyi, T., Twenty-Fifth Symposium (International) on Combustion, The Combustion Institute, Pittsburgh, pp. 949-955, 1994.

13. Griffiths, J.F., Prog. Energy Combust. Sci. 21:25107, 1995 .

14. Baurle, R.A., Mathur, T., Gruber, M.R., and Jackson, K.R., AIAA Paper 98-3121, 1998.

15. Westbrook, C.K., and Pitz, W.J., Combust. Sci. and Tech. 37:117-152, 1984.

16. Chen, J.-Y. and Chang, W.C., Twenty-Sixth Symposium (International) on Combustion, The Combustion Institute, Pittsburgh, pp. 2207-2214, 1997.

17. Mallampalli, H.P., Fletcher, T.H. and Chen, J.-Y., Journal of Engineering for Gas Turbines and Power, 120:703-712, 1998.

18. Sung, C.J., Law, C.K. and Chen, J.-Y., TwentySeventth Symposium (International) on Combustion, The Combustion Institute, Pittsburgh, pp. 195-304, 1998.

19. Glarborg, P., Kee, R.J., Grcar, J.F., and Miller, J.A., Sandia National Laboratories Report SAND86-8209, 1986.

20. Singh, D.J., and Jachimowski, C.J., AIAA Journal 32:213-215, 1994.

21. Lutz, A.E., Kee, R.J., and Miller, J.A., Sandia National Laboratories Report SAND87-8248, 1987.

22. Vermeer, D.J., Meyer, J.W., and Oppenheim, A.K., Combust. Flame 18:327-336, 1972.

This work was performed under the auspices of the U.S. Department of Energy by the University of California, Lawrence Livermore National Laboratory under Contract No. W-7405-Eng-48. 
Table 1. Characteristics of Reduced Mechanisms.

\begin{tabular}{|c|c|c|c|}
\hline Mechanism & $\begin{array}{l}\text { No. of } \\
\text { steps }\end{array}$ & $\begin{array}{l}\text { No. of } \\
\text { species }\end{array}$ & Species included \\
\hline ethylene 10 & 6 & 10 & $\mathrm{H}_{2}, \mathrm{O}_{2}, \mathrm{OH}, \mathrm{H}_{2} \mathrm{O}, \mathrm{CO}, \mathrm{CO}_{2}, \mathrm{C}_{2} \mathrm{H}_{2}, \mathrm{C}_{3} \mathrm{H}_{3}, \mathrm{C}_{2} \mathrm{H}_{4}, \mathrm{~N}_{2}$ \\
\hline $\begin{array}{l}\text { ethylene } 10 \\
\text { (ignition) }\end{array}$ & 6 & 10 & $\mathrm{H}, \mathrm{H}_{2}, \mathrm{O}, \mathrm{O}_{2}, \mathrm{OH}, \mathrm{H}_{2} \mathrm{O}, \mathrm{CO}, \mathrm{CO}_{2}, \mathrm{C}_{2} \mathrm{H}_{4}, \mathrm{~N}_{2}$ \\
\hline ethylene 15 & 11 & 15 & $\begin{array}{l}\mathrm{H}, \mathrm{H}_{2}, \mathrm{O}, \mathrm{O}_{2}, \mathrm{OH}, \mathrm{H}_{2} \mathrm{O}, \mathrm{CO}, \mathrm{CO}_{2}, \mathrm{CH}_{3}, \mathrm{CH}_{4}, \mathrm{C}_{2} \mathrm{H}_{2}, \mathrm{C}_{2} \mathrm{H}_{3}, \\
\mathrm{C}_{3} \mathrm{H}_{3}, \mathrm{C}_{2} \mathrm{H}_{4}, \mathrm{~N}_{2}\end{array}$ \\
\hline $\begin{array}{l}\text { ethylene } 15 \\
\text { (ignition) }\end{array}$ & 11 & 15 & $\begin{array}{l}\mathrm{H}, \mathrm{H}_{2}, \mathrm{O}, \mathrm{O}_{2}, \mathrm{OH}, \mathrm{H}_{2} \mathrm{O}, \mathrm{CO}, \mathrm{CO}_{2}, \mathrm{CH}_{4}, \mathrm{HO}_{2}, \mathrm{CH}_{2} \mathrm{O} \\
\mathrm{C}_{2} \mathrm{H}_{2}, \mathrm{C}_{2} \mathrm{H}_{3}, \mathrm{C}_{2} \mathrm{H}_{4}, \mathrm{~N}_{2}\end{array}$ \\
\hline ethylene 20 & 16 & 20 & $\begin{array}{l}\mathrm{H}, \mathrm{H}, \mathrm{O}, \mathrm{O}, \mathrm{OH}, \mathrm{H}, \mathrm{O}, \mathrm{CO}, \mathrm{CO}_{2}, \mathrm{CH}_{3}, \mathrm{CH}_{4}, \mathrm{CH}, \mathrm{O}, \mathrm{C}, \mathrm{H}, \\
\mathrm{C}_{2} \mathrm{H}_{2}, \mathrm{C}_{2} \mathrm{H}_{3}, \mathrm{CH}_{2} \mathrm{CO}, a-\mathrm{C}_{3} \mathrm{H}_{4}, p-\mathrm{C}_{3} \mathrm{H}_{4}, \mathrm{C}_{3} \mathrm{H}_{3}, \mathrm{C}_{2} \mathrm{H}_{4}, \mathrm{~N}_{2}\end{array}$ \\
\hline $\begin{array}{l}\text { ethylene } 20 \\
\text { (ignition) }\end{array}$ & 16 & 20 & $\begin{array}{l}\mathrm{H}, \mathrm{H}_{2}, \mathrm{O}, \mathrm{O}_{2}, \mathrm{OH}, \mathrm{H}_{2} \mathrm{O}, \mathrm{CO}, \mathrm{CO}_{2}, \mathrm{HCO}, \mathrm{CH}_{3}, \mathrm{CH}_{4}, \mathrm{HO}_{2}, \\
\mathrm{CH}_{2} \mathrm{O}, \mathrm{CH}, \mathrm{C}_{2} \mathrm{H}, \mathrm{C}_{2} \mathrm{H}_{2}, \mathrm{C}_{2} \mathrm{H}_{3}, \mathrm{CH}_{2} \mathrm{CO}, \mathrm{C}_{2} \mathrm{H}_{4}, \mathrm{~N}_{2}\end{array}$ \\
\hline HMD9 & 5 & 9 & $n-\mathrm{C}_{7} \mathrm{H}_{16}, \mathrm{O}_{2}, \mathrm{CO}, \mathrm{CO}_{2}, \mathrm{C}_{2} \mathrm{H}_{2}, \mathrm{H}, \mathrm{H}_{2}, \mathrm{H}_{2} \mathrm{O}, \mathrm{N}_{2}$ \\
\hline HMD12 & 8 & 12 & $n-\mathrm{C}_{7} \mathrm{H}_{16}, \mathrm{O}_{2}, \mathrm{CO}, \mathrm{CO}_{2}, \mathrm{CH}_{2}, \mathrm{C}_{2} \mathrm{H}_{2}, \mathrm{H}, \mathrm{O}, \mathrm{H}_{2}, \mathrm{H}_{2} \mathrm{O}, \mathrm{OH}, \mathrm{N}_{2}$ \\
\hline HMD16 & 12 & 16 & $\begin{array}{l}n-\mathrm{C}_{7} \mathrm{H}_{16}, \mathrm{O}_{2}, \mathrm{C}_{2} \mathrm{H} 4, \mathrm{CO}, \mathrm{CO}_{2}, \mathrm{CH}_{4}, \mathrm{C}_{6} \mathrm{H}_{6}, \mathrm{C}_{2} \mathrm{H}_{2}, \mathrm{CH}_{3}, \\
\mathrm{CH}_{2} \mathrm{CO}, \mathrm{H}, \mathrm{O}, \mathrm{H}_{2}, \mathrm{H}_{2} \mathrm{O}, \mathrm{OH}, \mathrm{N}_{2}\end{array}$ \\
\hline CGPW 16 & 12 & 16 & $\begin{array}{l}n-\mathrm{C}_{7} \mathrm{H}_{16}, \mathrm{H}, \mathrm{H}_{2}, \mathrm{O}, \mathrm{O}_{2}, \mathrm{OH}, \mathrm{H}_{2} \mathrm{O}, \mathrm{CO}, \mathrm{CO}_{2}, \mathrm{CH}_{3}, \mathrm{CH}_{4}, \\
\mathrm{C}_{2} \mathrm{H}_{6}, \mathrm{C}_{2} \mathrm{H}_{4}, \mathrm{C}_{2} \mathrm{H}_{2}, \mathrm{C}_{3} \mathrm{H}_{3}, \mathrm{~N}_{2}\end{array}$ \\
\hline CGPW20 & 16 & 20 & $\begin{array}{l}n-\mathrm{C}_{7} \mathrm{H}_{16}, \mathrm{H}, \mathrm{H}_{2}, \mathrm{O}, \mathrm{O}_{2}, \mathrm{OH}, \mathrm{H}_{2} \mathrm{O}, \mathrm{CO}, \mathrm{CO}_{2}, \mathrm{CH}_{3}, \mathrm{CH}_{4}, \\
\mathrm{HO}_{2}, \mathrm{CH}_{2} \mathrm{O}, \mathrm{C}_{2} \mathrm{H}_{6}, \mathrm{C}_{2} \mathrm{H}_{4}, \mathrm{C}_{2} \mathrm{H}_{5}, \mathrm{C}_{2} \mathrm{H}_{2}, \mathrm{C}_{3} \mathrm{H}_{6}, \mathrm{C}_{3} \mathrm{H}_{3}, \mathrm{~N}_{2}\end{array}$ \\
\hline CGPW25 & 21 & 25 & $\begin{array}{l}n-\mathrm{C}_{7} \mathrm{H}_{16}, \mathrm{H}, \mathrm{H}_{2}, \mathrm{O}, \mathrm{O}_{2}, \mathrm{OH}, \mathrm{H}_{2} \mathrm{O}, \mathrm{CO}, \mathrm{CO}_{2}, \mathrm{CH}_{3}, \mathrm{CH}_{4}, \\
\mathrm{HO}_{2}, \mathrm{H}_{2} \mathrm{O}_{2}, \mathrm{CH}_{2} \mathrm{O}, \mathrm{C}_{2} \mathrm{H}_{6}, \mathrm{C}_{2} \mathrm{H}_{4}, \mathrm{C}_{2} \mathrm{H}_{5}, \mathrm{C}_{2} \mathrm{H}_{2}, \mathrm{CH}_{3} \mathrm{OH}, \\
\mathrm{CH}_{2} \mathrm{CO}, a-\mathrm{C}_{3} \mathrm{H}_{4}, p-\mathrm{C}_{3} \mathrm{H}_{4}, \mathrm{C}_{3} \mathrm{H}_{6}, \mathrm{C}_{3} \mathrm{H}_{3}, \mathrm{~N}_{2}\end{array}$ \\
\hline
\end{tabular}




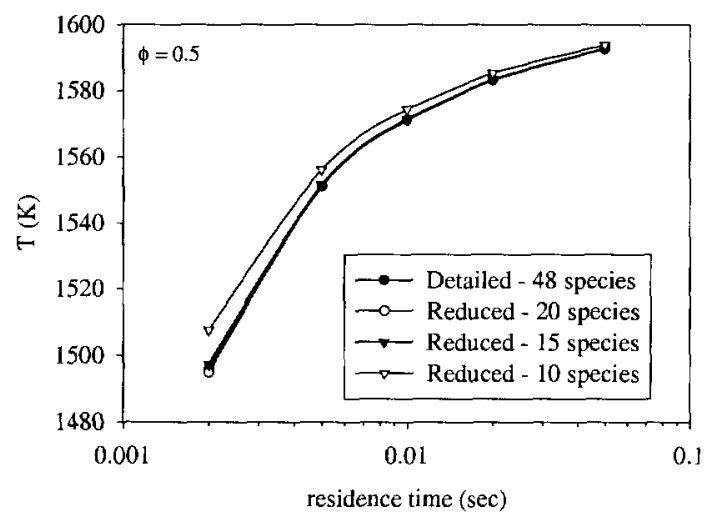

Figure 1. Comparison of adiabatic PSR solutions for ethylene/air at $1.0 \mathrm{~atm}$., inlet temperature $=$ $300 \mathrm{~K}$, equivalence ratio $=0.5$

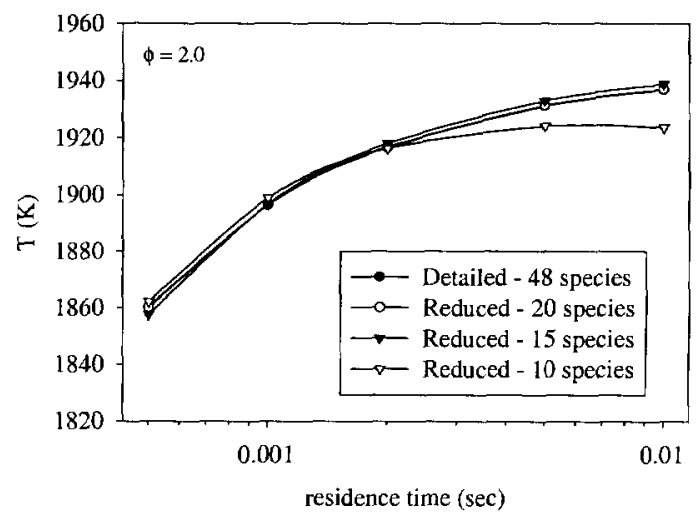

Figure 3. Comparison of adiabatic PSR solutions for ethylene/air at $1.0 \mathrm{~atm}$., inlet temperature = $300 \mathrm{~K}$, equivalence ratio $=2.0$

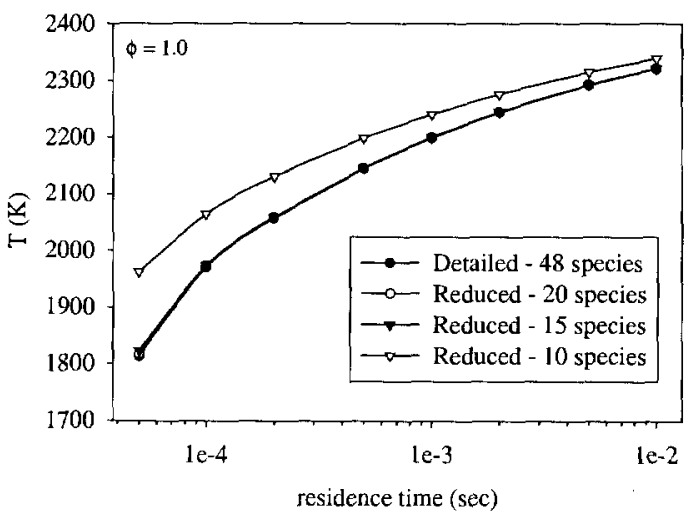

Figure 2. Comparison of adiabatic PSR solutions for ethylene/air at $1.0 \mathrm{~atm}$., inlet temperature = $300 \mathrm{~K}$, equivalence ratio $=1.0$

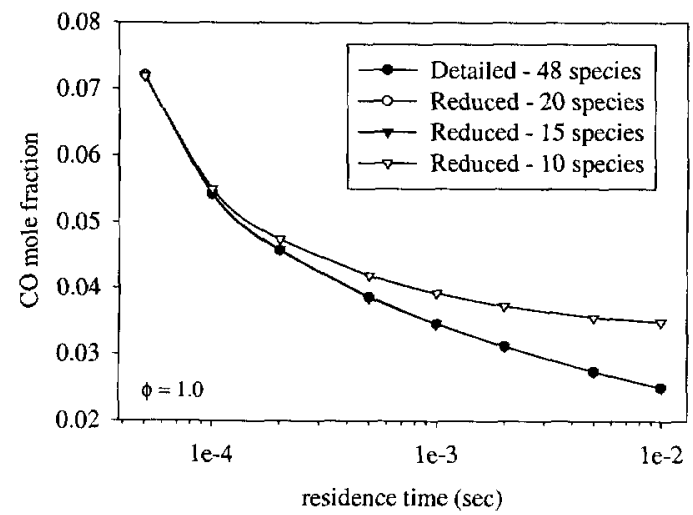

Figure 4. Comparison of adiabatic PSR solutions for ethylene/air at $1.0 \mathrm{~atm}$., inlet temperature = $300 \mathrm{~K}$, equivalence ratio $=1.0$ 


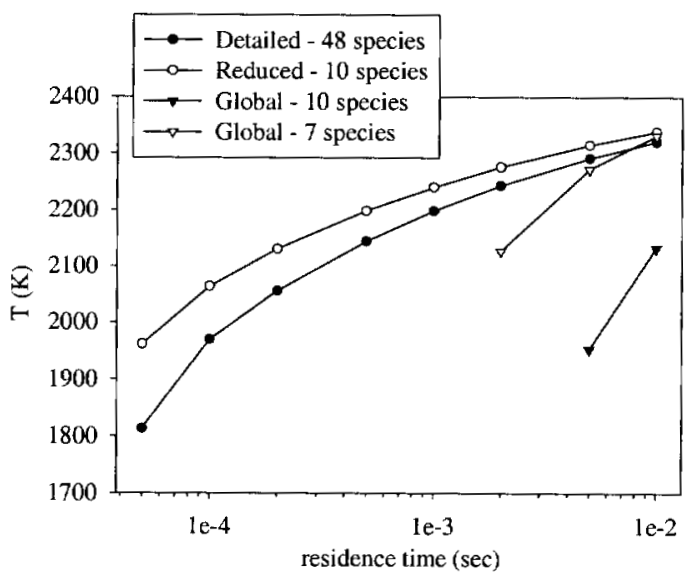

Figure 5. Comparison of adiabatic PSR solutions for ethylene/air at $1.0 \mathrm{~atm}$., inlet temperature = $300 \mathrm{~K}$, equivalence ratio $=1.0$.

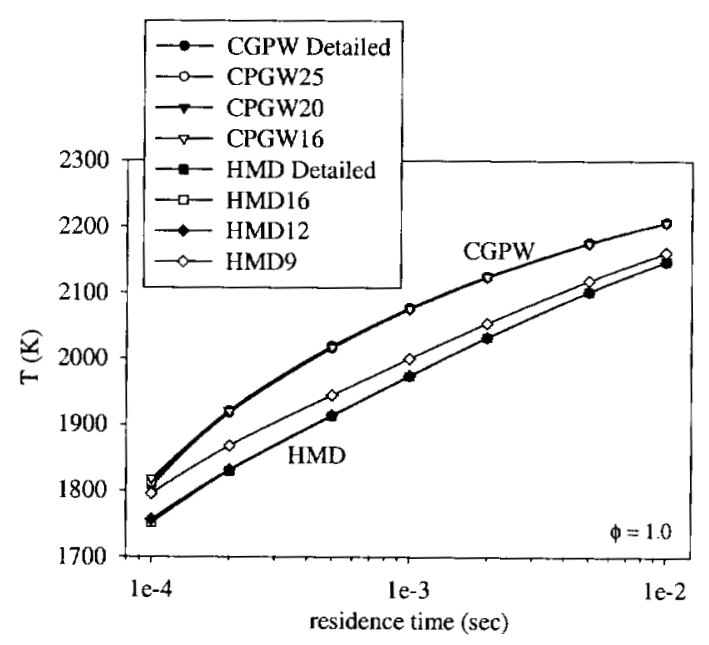

Figure 7. Comparison of adiabatic PSR solutions for $n$-heptane/air at $1.0 \mathrm{~atm}$., inlet temperature = $300 \mathrm{~K}$, equivalence ratio $=1.0$.

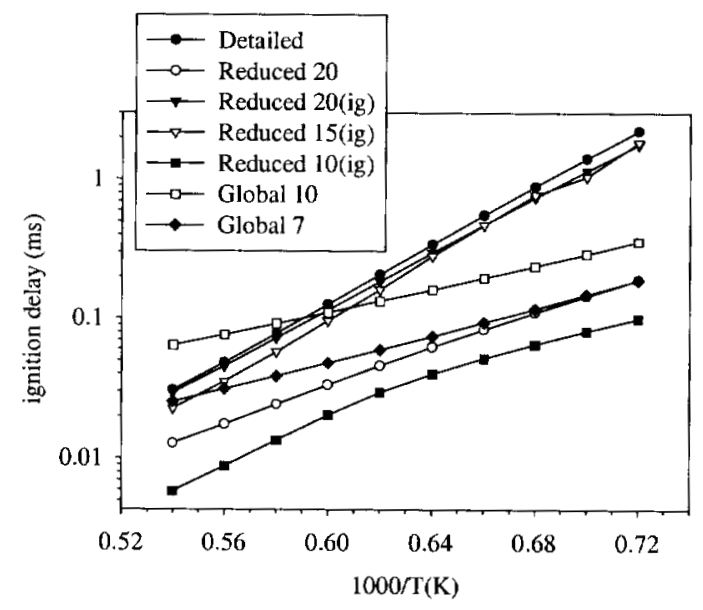

Figure 6. Comparison of calculated ignition delay times for ethylene/air at $1.0 \mathrm{~atm}$., equivalence ratio $=1.0$.

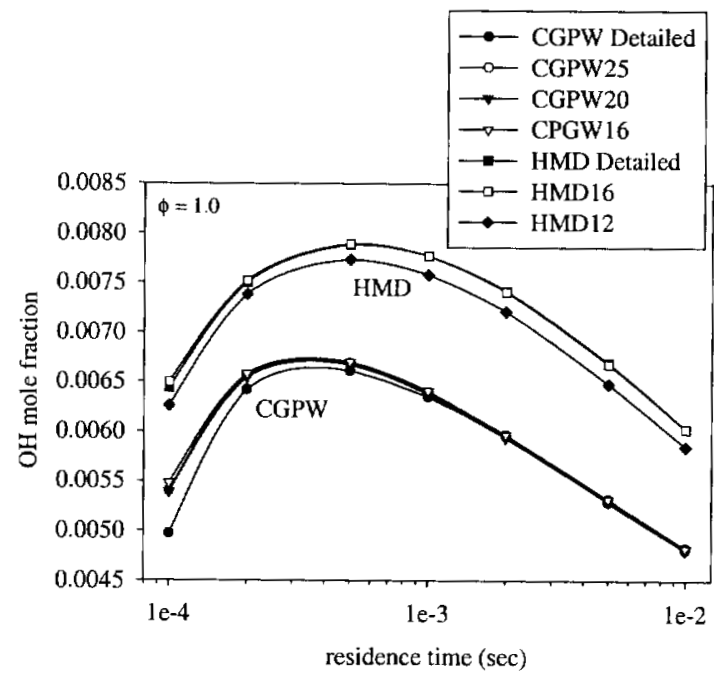

Figure 8. Comparison of adiabatic PSR solutions for $n$-heptane/air at $1.0 \mathrm{~atm}$., inlet temperature = $300 \mathrm{~K}$, equivalence ratio $=1.0$. 


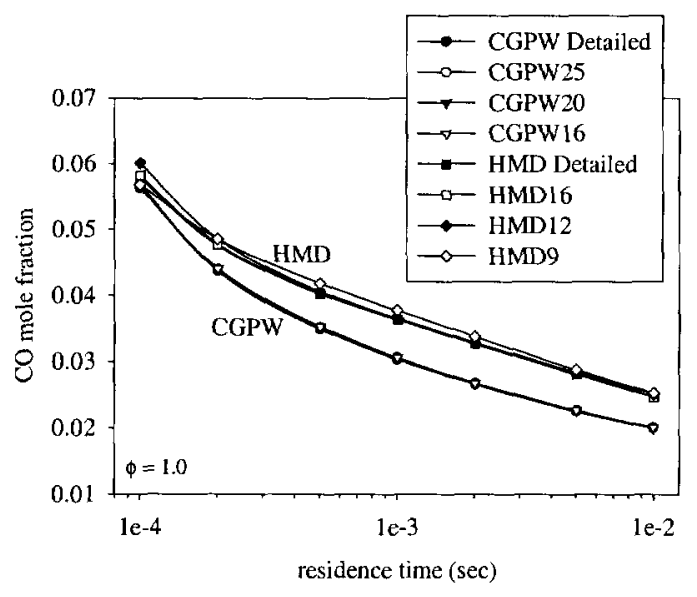

Figure 9. Comparison of adiabatic PSR solutions for $n$-heptane/air at $1.0 \mathrm{~atm}$., inlet temperature = $300 \mathrm{~K}$, equivalence ratio $=1.0$.

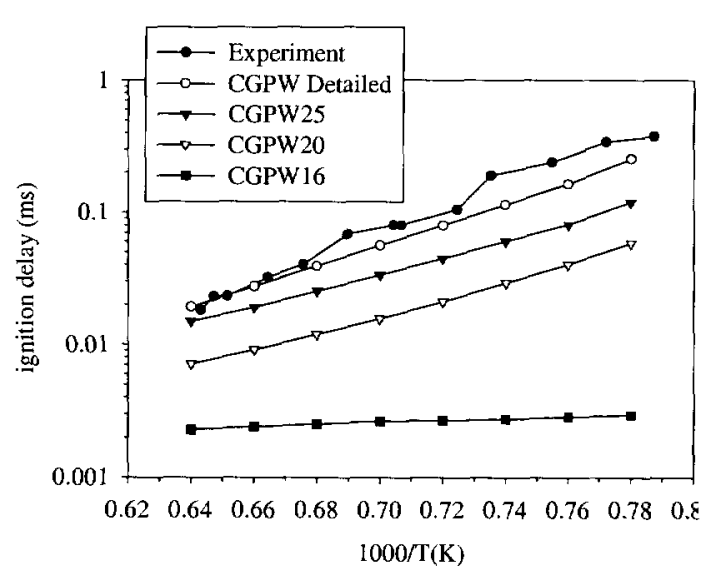

Figure 11. Comparison of measured ${ }^{22}$ and calculated ignition delay times for $70 \% \mathrm{Ar}, 27.5 \%$ $\mathrm{O}_{2}, 2.5 \% n$-heptane initially at $2.5 \mathrm{~atm}$., for the CGPW $^{3}$ mechanism and reduced mechanisms based on it.

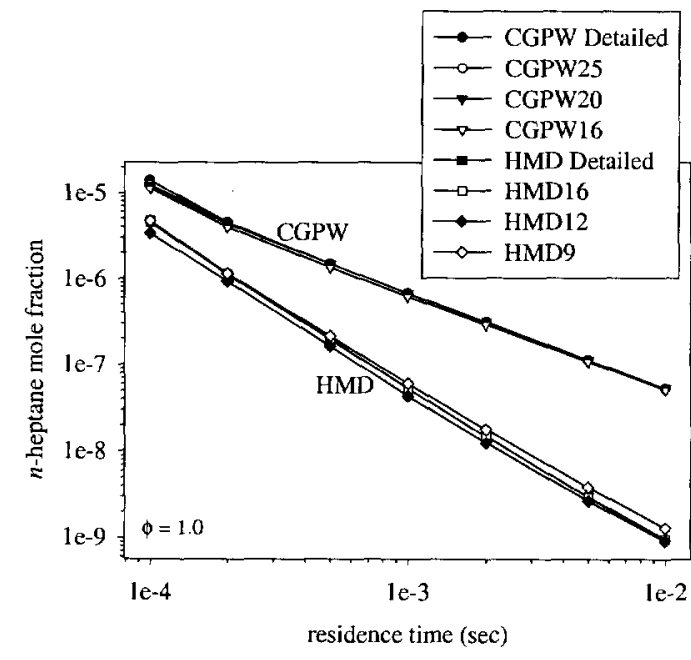

Figure 10. Comparison of adiabatic PSR solutions for $n$-heptane/air at $1.0 \mathrm{~atm}$., inlet temperature = $300 \mathrm{~K}$, equivalence ratio $=1.0$.

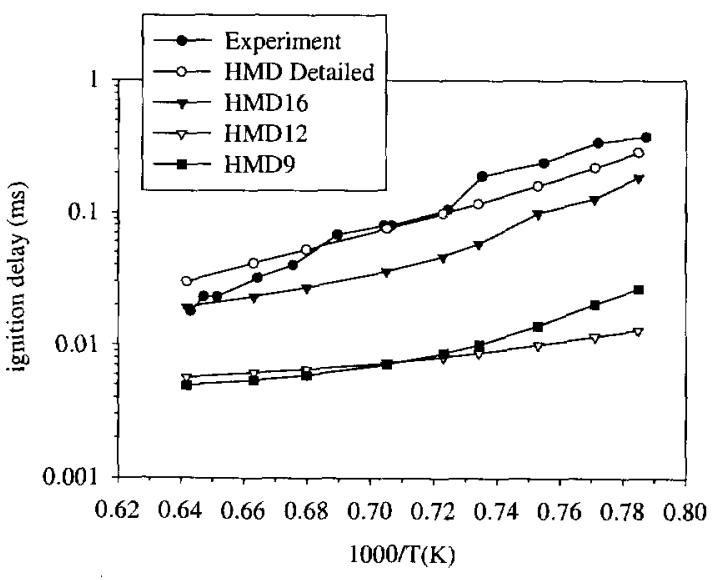

Figure 12. Comparison of measured ${ }^{22}$ and calculated ignition delay times for $70 \% \mathrm{Ar}, 27.5 \%$ $\mathrm{O}_{2}, 2.5 \% n$-heptane initially at $2.5 \mathrm{~atm}$., for the $\mathrm{HMD}^{2}$ mechanism and reduced mechanisms based on it. 